\title{
0099 SAFETY MANAGEMENT ON BUS RAPID TRANSIT CORRIDOR DELHI: PROCESS AND OUTCOMES
}

S Gandhi*, G Tiwari, A Singh Correspondence: S G Architects, 6151/8, Sector D, Pocket 6, Vasant Kunj, New Delhi, 110070, India

\subsection{6/ip.2010.029215.99}

Introduction Delhi government operationalised $5.8 \mathrm{~km}$, phase- 1 length of ( $14.8 \mathrm{~km}$ long) bus rapid transit system corridor in April 2008. First 6 months of operations witnessed six fatal accidents as against an annual average of nine during the preconstruction period; prompting this study to find reasons and measure efficacy of interventions.

Method The corridor operator, Delhi Integrated Multi-Modal Transit System, introduced monitoring processes, based on which interventions were planned to improve operations and safety. The study included assessment of various interventions, over a period of 16 months postoperations. These included channelisation of pedestrian crossings and introduction of rumble strips to reduce bus speeds. The analysis of the study was conducted in two parts. First part included comparison of accident trends and second part included study of conflicts postinterventions.

Results Fatal accident rate increased by $30 \%$, over preconstruction period, in first 6 months of operations. Type of 


\section{IP Safety 2010 abstracts}

victims postconstruction were only pedestrians as against a mix of pedestrians, cyclists and motorists earlier.

All accidents were limited to conflicts with buses within bus lane with $85 \%$ occurring near bus shelter. Fatalities dropped to 'ZERO' postintroduction of rumble strips. Instances of buses speeding over $60 \mathrm{~km} / \mathrm{h}$ fell by $67 \%$. Pedestrians crossing bus lanes increased by $23 \%$.

Conclusion Channelisation of pedestrian crossing did not result in reduced conflicts; however reduction in speeds were achieved through implementation of rumble strips. The study concludes that it is possible to achieve zero death targets on road systems by introducing consistent, monitoring-based intervention processes. 